\title{
Studying of Common Factors Affecting Reading of Lithium Fluoride Thermo-Luminescence Dosimeter Crystal
}

\author{
Mohammed A. Ali Omer1,2, Abdulrahman A. Alsayyari'1, Jumaa Y. Tamboul³, Rowida B. Ali², \\ Amira A. Ahmed ${ }^{4}$, Ahmed Abukonna ${ }^{2}$ \\ ${ }^{1}$ Department of Radiologic Technology, College of Applied Medical Science, Qassim University, Buraidah, KSA \\ ${ }^{2}$ Department of Radiotherapy, College of Medical Radiologic Science, Sudan University of Science \& Technology, Khartoum, Sudan \\ ${ }^{3}$ Department of Diagnostic Radiologic Technology, College of Applied Medical Sciences, Taibah University, Medina, KSA \\ ${ }^{4}$ Department of Radiation Safeties, Sudan Atomic Energy Commission, Khartoum, Sudan \\ Email:alkajam@gmail.com, a.alsayyari@qu.edu.sa,rowidabushra2010@gmail.com,jtamboul@hotmail.com, \\ ameeraabdo2003@yahoo.com,konaa17@hotmail.com
}

How to cite this paper: Omer, M.A.A., Alsayyari, A.A., Tamboul, J.Y., Ali, R.B., Ahmed, A.A. and Abukonna, A. (2017) Studying of Common Factors Affecting Reading of Lithium Fluoride Thermo-Luminescence Dosimeter Crystal. Open Journal of Biophysics, 7, 14-24.

http://dx.doi.org/10.4236/ojbiphy.2017.71002

Received: November 26, 2016

Accepted: December 24, 2016

Published: December 27, 2016

Copyright $\odot 2017$ by authors and Scientific Research Publishing Inc. This work is licensed under the Creative Commons Attribution International License (CC BY 4.0).

http://creativecommons.org/licenses/by/4.0/

cC) (i) Open Access

\begin{abstract}
The aim of this study was to study the technical factors affecting the reading of TLD (LiF:Mg:Ti) for radiation dosimetry. The method adapted was an exposure of LiF:Mg:Ti crystal with $\gamma$-ray with the following filters ( $\mathrm{Hp} 0.07$ and Hp 10), before and after usage of filter $\mathrm{Hp}$ (0.07), annealing, cooling by nitrogen flux and crystal morphology by scanning electron microscope. The collected data analyzed by EXCELL software showed that: TLD average count/second (C/s) with filter Hp (10) was greater than that obtained with filter $\mathrm{Hp}(0.07)$ with an amount of $1191 \mathrm{c} / \mathrm{s}$ (19\%). Also the analysis showed that: the average C/s without filter Hp (0.07) was greater than that with filter by an amount of $994.5 \mathrm{C} / \mathrm{s}(16.4 \%)$, and there was proportional linear relationship; as the applied dose increased the TLD C/s increased significantly $\left(R^{2}=0.9\right)$ based on the equations: $y=885.1 x-286.5$ and $y=860.5 x+$ 856.8 for filtered and without filtered beam respectively, where $x$ refers to applied dose in $\mathrm{mGy}$ and $y$ refers to $\mathrm{C} / \mathrm{s}$. Also the average $\mathrm{C} / \mathrm{s}$ without nitrogen flux (cooling) was greater than with nitrogen count with an amount of $52.4 \mathrm{C} / \mathrm{s}(11 \%)$. The annealing (without filter) causes a reduction in dose by $82.2 \mu \mathrm{Gy}(19.2 \%)$, and in case of annealing with filter, the dose reduced by $66.7 \mu \mathrm{Gy}$ (21.9\%) relative to annealing without filter. The morphology of TLD crystal shown by scanning electron microscope SEM was a darkening surface after irradiation.
\end{abstract}

\section{Keywords}

Radiation, Effects, Dosimeter, Factors, Thermoluminescence

\section{Introduction}

Thermo-luminescence dosimeters (TLD) as radiation detectors imply more than two 
thousand (2000) types; among them only eight (8) are most common in the field of radiation dosimetry. These eight types which could be divided into tissue equivalent materials which imply Beryllium Oxide (BeO) [1], Lithium Borate $\left(\mathrm{Li}_{2} \mathrm{~B}_{4} \mathrm{O}_{7}\right)$, Lithium Fluoride (LiF) [2], and Magnesium Borate $\left(\mathrm{MgB}_{4} \mathrm{O}_{7}\right)$ with low atomic number $(\mathrm{Z})$ hence have been utilized for medical, personal and industrial applications. And the non-tissue equivalent materials that include Calcium Sulphate $\left(\mathrm{CaSO}_{4}\right)$ [3], Calcium Fluoride $\left(\mathrm{CaF}_{2}\right)$, Aluminum Oxide $\left(\mathrm{Al}_{2} \mathrm{O}_{3}\right)$ and magnesium orthosilicate $\left(\mathrm{Mg}_{2} \mathrm{SiO}_{4}\right)$ are high atomic number $(Z)$ with high sensitivity used for environmental monitoring. The TLDs may be used in an extended range of occupational exposures from low level as in conventional radiography to those of high risk such as angiography, nuclear medicine and radiotherapy in addition; any decisions made by regulatory bodies for the workers are based on the results of personal dosimeters in comparison with different dose limits. However, TLD would have a calibration process and as a result, reading or signal stability could be influenced by different factors; these factors imply (temperature, pressure, long term radiation exposure, moisture) and their relevant effects could be expressed in the followings: 1) The effect of heating time in TLD reading has been shown and expressed by Al-Haj \& Lagarde [4], in a form of glow curve changes which they ascribed to phenomenon of fading which should be less than 5\% [5] and the distortion of the glow curve due to anomalies in routine practice as shown in Figure 1.2) The temperature: as the TLD read out is sometimes restricted to the applied temperature and dosimeter design such as the thickness as stated by Stadtmann et al. [6] and expressed in Figure 2, however such effect has been discussed and a practical solving introduced by Kitis et al. [7]. 3) The filter: as it has been used to correct the energy

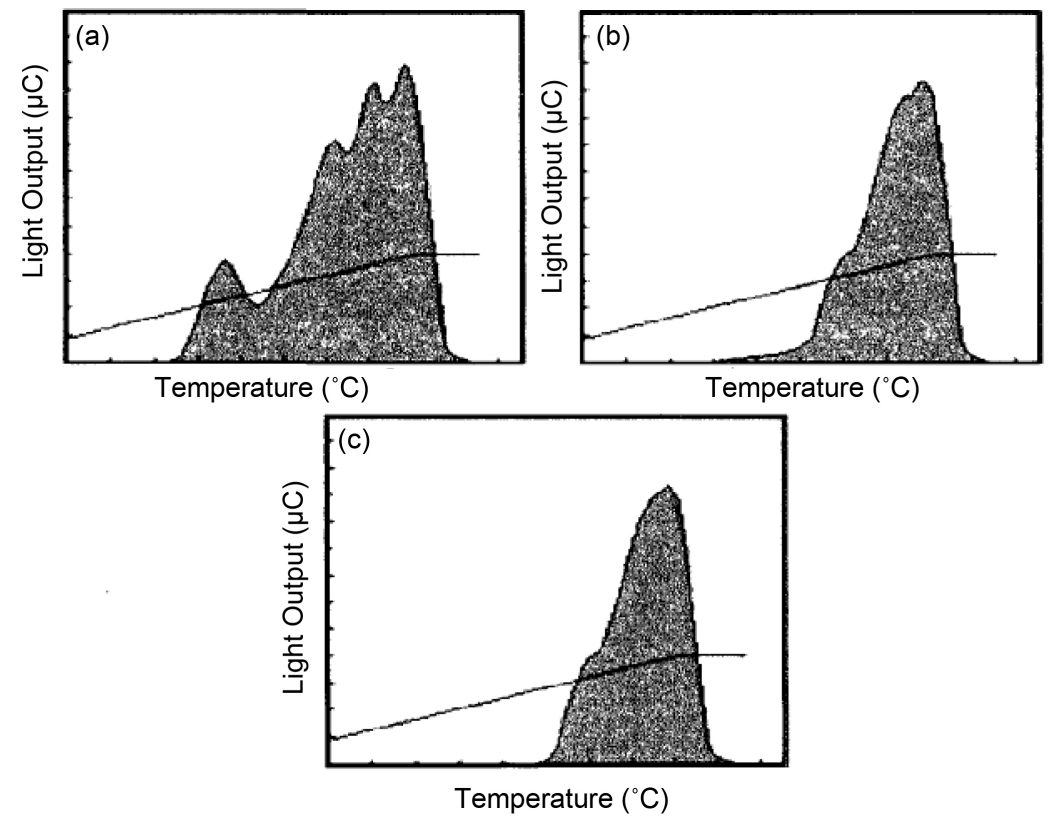

Figure 1. Glow curve for LiF:Mg exposed to equal doses of radiation and read at different times post exposure. The solid line depicts the temperature of the TL crystal as a function of time. (a) is the glow curve measured shortly after irradiating, (b) was read one month post exposure and (c) was read three months after exposure [4]. 


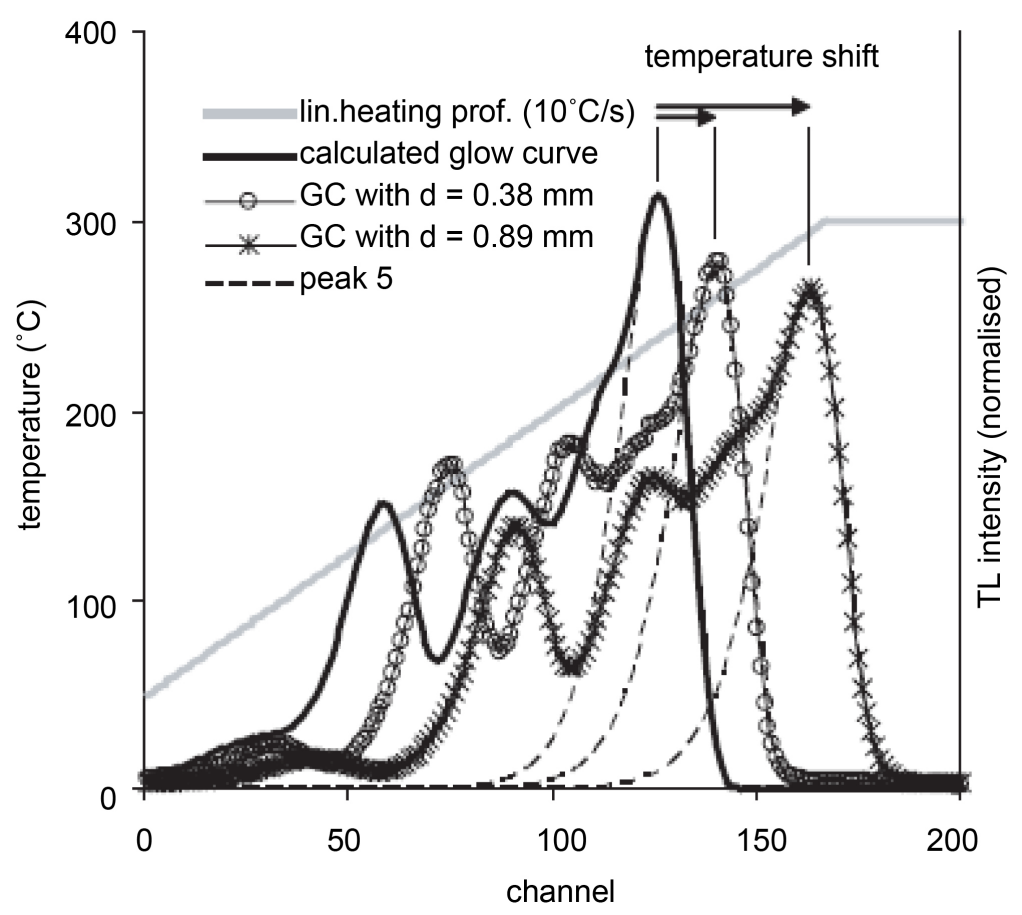

Figure 2. Shows the comparison of the calculated glow curve (GC) (kinetic parameters derived with GCDC at low heating rate or $\left.1^{\circ} \mathrm{C} \cdot \mathrm{s}^{-1}\right)$ for $\mathrm{LiF}: \mathrm{Mg}: \mathrm{Ti}$ and the measured GCs for two different detector thicknesses. The observed shift of the measured GCs is indicated with an arrow [6].

dependence of TL material, achieving equivalent doses (used to obtain deep dose rates inside a human body), and filtering out unwanted particles, and 4) to correct for backscatter. Hence reading of TLD with or without filter will induce significant change in the final measured dose and achieving energy independence in TL phosphors [8]. The applied TLD in radiation dosimeter composed of four different TL phosphors and filters. The first one is a thin Mylar window which gives protection from sunlight exposure and insignificant attenuation to incident radiation and used to measure skin dose. The second filter is a tissue equivalent polymer with a density thickness equal to $1 \mathrm{~cm}$ of tissue and utilized to determine the deep dose to an individual as well for whole body external dose. The third filtered TL contains hydrogenous material, such as acrylonitrile butadiene styrene (ABS), to be applicable with neutrons beam. The fourth filter consists of low atomic number material foil such as copper to attenuate any beta particles and to measure only the dose contribution coming from photons [9]. More factors influencing the TLD reading or signal are the pressure and repeated radiation exposure that could influence even the crystallization of TLD chips. In relation to these influencing factors; Lee et al. [10] have developed a technique to reduce the fading effects of repeated radiation exposure in TLD crystal that leads to signal loss of about $15 \%$ to only $5 \%$. The annealing process before usage of TLD in measurement, and as well the nitrogen for cooling have also some influence in TLD reading in addition to spurious effects due to heat exposure, friction and atmosphere [11]. Since the desirable criteria of the phosphors materials used in radiation detectors are: sensitivity, stability of traps and activators and host lattice, long term storage of information, simple glue curve, and spectrum 
with short wavelength as stated by Fowler and Attix [2], and Mahmoud and Iskandar, [12], the studies and attempts to highlight the factors influencing the TLD reading and the relevant solving methods have to be necessary and under focus by many scholars; hence the trend of the current study is to reveal the effects of some technical factors in TLDs reading.

\section{Methodology}

\subsection{Materials}

- Manual TLD-Reader RA'04 is Reader-Analyzer new system which used in this study

- TLD pellets and their holder (LiF:Mg:Ti)

- Annealing oven for thermo luminescent dosimeter

- Gamma radiation source which was Cs-137 source

- Reference Ionization Chamber

- Transmission electron microscope TEM

- Barometer

\subsection{Method}

A total of fifty TLDs chip have been used in this study, situated in 25 holders each fit for two pellets defined as shallow dose $\mathrm{Hp}$ (0.07) and deep dose Hp (10). All pellets have been used with and without annealing at oven up to $400^{\circ} \mathrm{C}$, with/without build up (Hp 0.07 \& Hp 10), with/without cooling by nitrogen flux. For measuring the zero doses (ZD), the TLDs placed on the tray of stainless steel which inserted to the oven $\left(400^{\circ} \mathrm{C}\right)$, then followed by fast cooling using nitrogen flux in some case and without cooling in other. Then the Zero doses have been measured (Background of pellet), and the average zero dose (ZD) has been calculated (with and without annealing) which in turn used to calculate Reader Calibration Factor (RCF) using the following equation:

$\mathrm{RCF}=($ Counts $)-($ Average zero doses $) /($ Dose of SSDL $)$, where the conversion factor from (secondary standard dose laboratory) SSDL to dose equivalent were 1.21 and 1.2 for shallow dose Hp (0.07) and deep dose Hp (10) respectively. Then the TLD chips irradiated by gamma radiation source (Ceasium-137) and receiving $0-15 \mathrm{mGy}$, then the counts have been measured by TLDs with consideration to with/without annealing, used/unused nitrogen cooling and the usage of buildup i.e. calculation at shallow depth $\mathrm{Hp}$ (0.07) and deep depth $\mathrm{Hp}(10)$ and the obtained counts have been converted to dose at shallow and deep depths by applying the following formulas:

$\mathrm{Hp}(0.07)=$ counts $/ \mu \mathrm{Gy} \times 1.21 \mathrm{mSv}$ and Deep dose $\mathrm{Hp}(10)=$ counts $/ \mu \mathrm{Gy} \times 1.21 \mathrm{mSv}$, respectively. And the final data have been analyzed using Microsoft EXCELL program in forms of bars and scattered correlation.

\section{Results}

The following section will highlight the results related to factors affecting the reading or the calibration of the TLD reader such as: reading of count/s with and without using filtration, with and without Nitrogen gas (cooling), with and without annealing (Zero dose reading) and the effect of dose in the chips structure. The results will be shown in forms of correlation, and bars. 


\section{Discussion}

Figure 3 shows the glow curve spectrum in correlation between the applied temperature

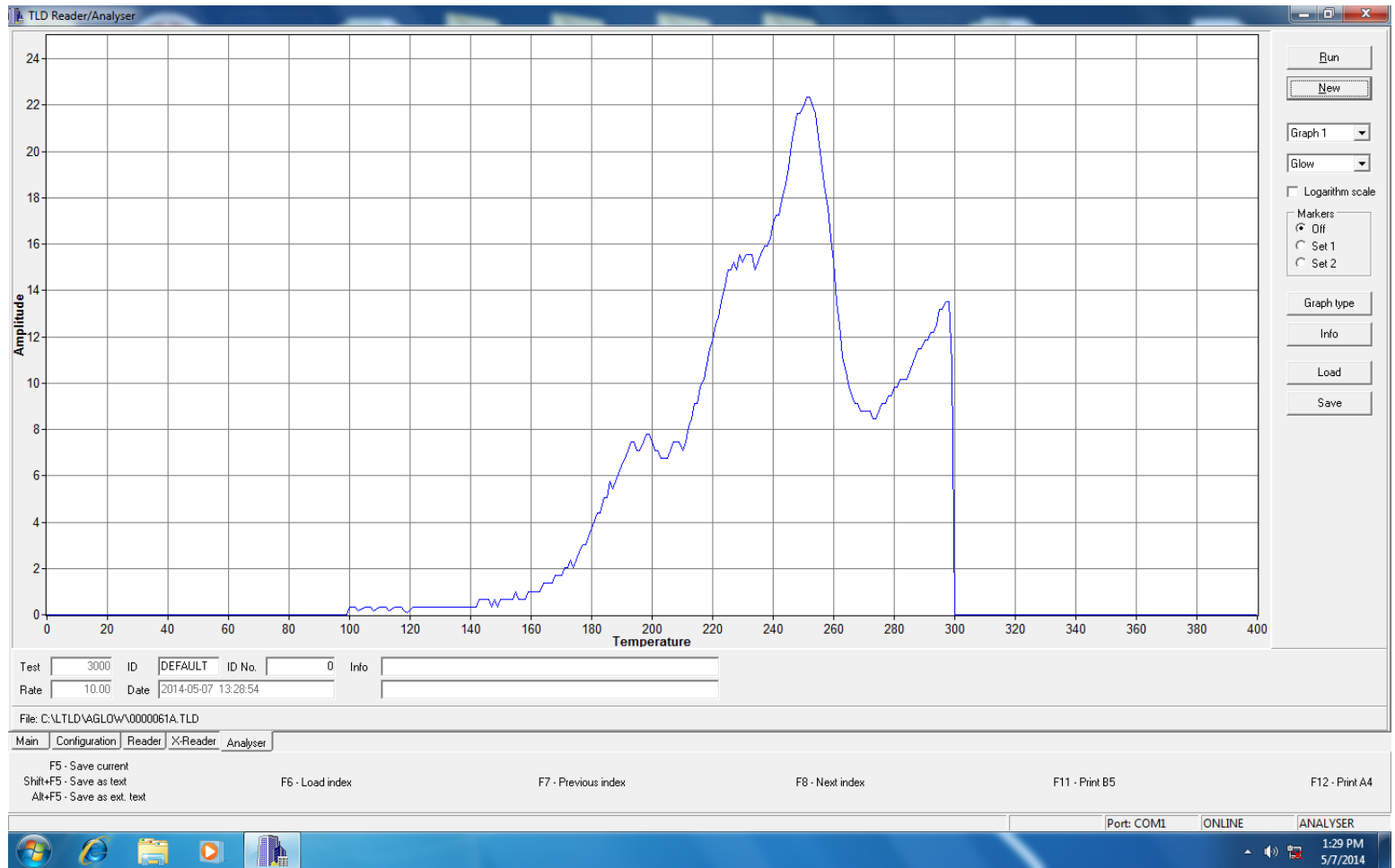

(a)

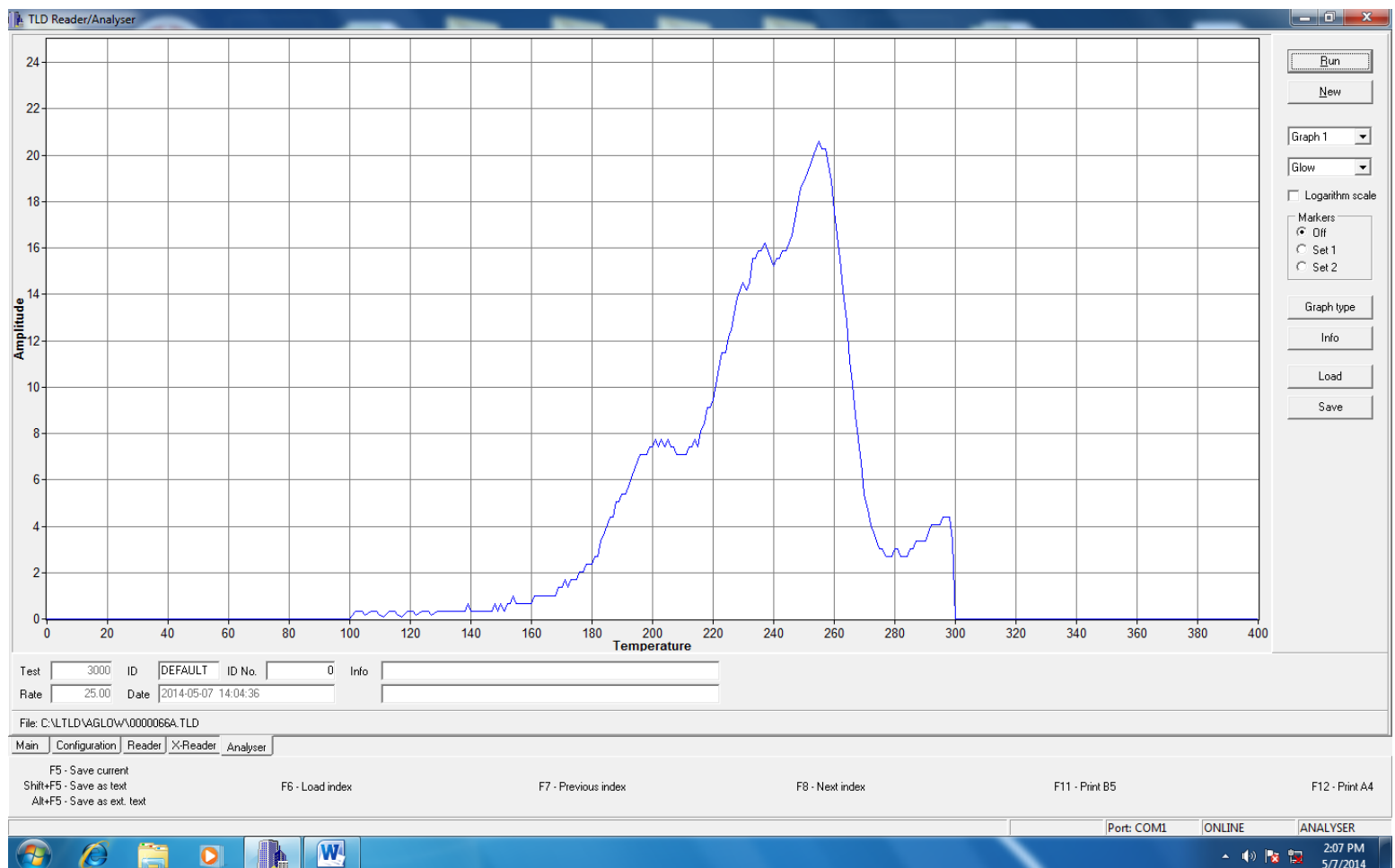

(b)

Figure 3. Shows the glow curve spectrum in correlation between applied temperature in ${ }^{\circ} \mathrm{C}$ versus amplitude using (a) filter Hp (10) and (b) filter Hp (0.07). 
in ${ }^{\circ} \mathrm{C}$ versus amplitude using (a) filter $\mathrm{Hp}(10)$ and (b) filter $\mathrm{Hp}$ (0.07) which is deduced and plotted in Figure 4 that correlate between the applied dose in mGy and the relative TLD count/s. The average TLD count/s with filter Hp (10) was greater than that obtained with filter $\mathrm{Hp}(0.07)$ with an amount of $1191 \mathrm{c} / \mathrm{s}$, (19\%) the high count at $\mathrm{Hp}$ (10) ascribed to the electronic range or the buildup region for $\gamma$-radiation whereas the count with Hp (0.07) refers to the count at the surface [13]. However Figure 5 shows the correlation between the applied irradiation dose in mGy and the count/s of TLD chips with and without filter Hp (0.07). The analysis reveals that: there was a proportional linear relationship between the applied dose and the TLD chips count for both cases with and without filter, and the correlation could be fitted in the form of equations: $y=885.1 x-286.5$ and $y=860.5 x+856.8$ for filtered and without filtered beam respectively, where $x$ refers to applied dose in $\mathrm{mGy}$ and $y$ refers to count/s. Such increment in count ascribed to increasing applied radiation dose; however the average counts/s

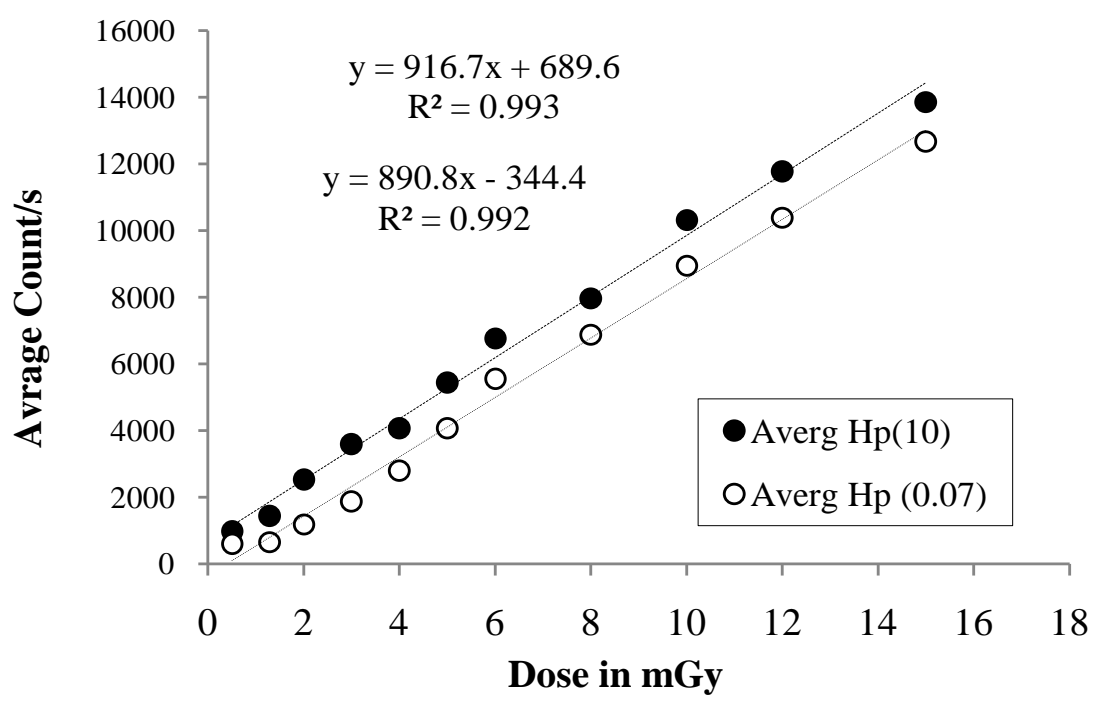

Figure 4. Shows the correlation between applied dose in mGy and the relative TLD count/s using filter $\mathrm{Hp}(0.07)$ and $\mathrm{Hp}(10)$.

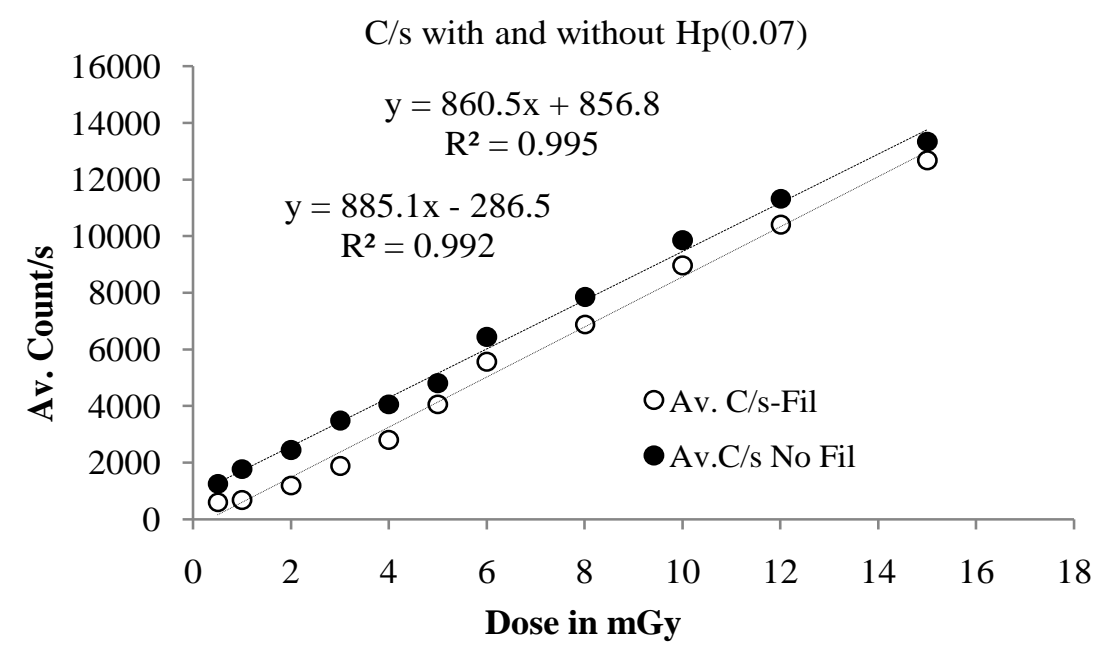

Figure 5. Shows the correlation between the applied irradiation dose in mGy and the count/s of TLD chips with and without filter (Hp (0.07)). 
with filter and without filter were 5064.5 and 6059.1 respectively i.e. the count without filter was greater than that with filter by an amount of $994.5 \mathrm{C} / \mathrm{s}$ (16.4\%). This result could be due to beam absorption [13] [14]. It has been noted by Pradhan et al. [15] that: the response of TLD crystal sandwiched between metal filters is less by a few percent than that of the bare crystal at $\mathrm{D}_{\max }$ depth in the phantom, whereas it is more (up to $29 \%$ ) for high energy photons. The decreased reading with filtered TLD crystal could be attributed to the attenuation due to metal filters at $D_{\max }$ depth in the phantom, whereas the increase in the response of discs under metal filters for high energy photons could be attributed to the contribution of the scattered secondary electrons produced by metal filters. Figure 6 shows the correlation between the number of TLD chip and the count/s of TLD chips received equal dose $(0.5 \mathrm{mGy})$ with and without Nitrogen flux for crystal cooling and no filter used. The study also shows that: the average count/s without nitrogen flux was greater than with nitrogen count despite the dose received by TLD chips was equal ( $0.5 \mathrm{mGy})$ with an amount of $52.4 \mathrm{C} / \mathrm{s}(11 \%)$; such result indicates the importance of system cooling during operation. Also there was a notation that: the count/s increases slightly with the number of chips being read; such increment in reading of count could be ascribed to an optimum annealing of the previous exposure, as the annealing is a sensitive case process.

Figure 7 shows the correlation between the chips number received equal dose $(0.5$ mGy) and the dose in $\mu \mathrm{Sv}$ measured by TLD chips before and after annealing (with and without reading zero dose-with filter). It reveals that: the doses measured without annealing (unread of zero doses), was so greater than that measured after annealing (reading of zero doses); this is due to accumulation of dose in case of reading without annealing (without reading zero dose) as the annealing usually empted and releasing the stored energy in the TLD chips [16]. Such variation in dose measurement with and without annealing could be ascribed to special annealing technique (heating at $400^{\circ} \mathrm{C}$ for $1 \mathrm{~h}$, quick cooling, then $80^{\circ} \mathrm{C}$ for 24 hours) required for $\mathrm{LiF}$ crystal and also due to spurious TL which influence the reading as well as the tribo-luminescence (Light $\lambda=$

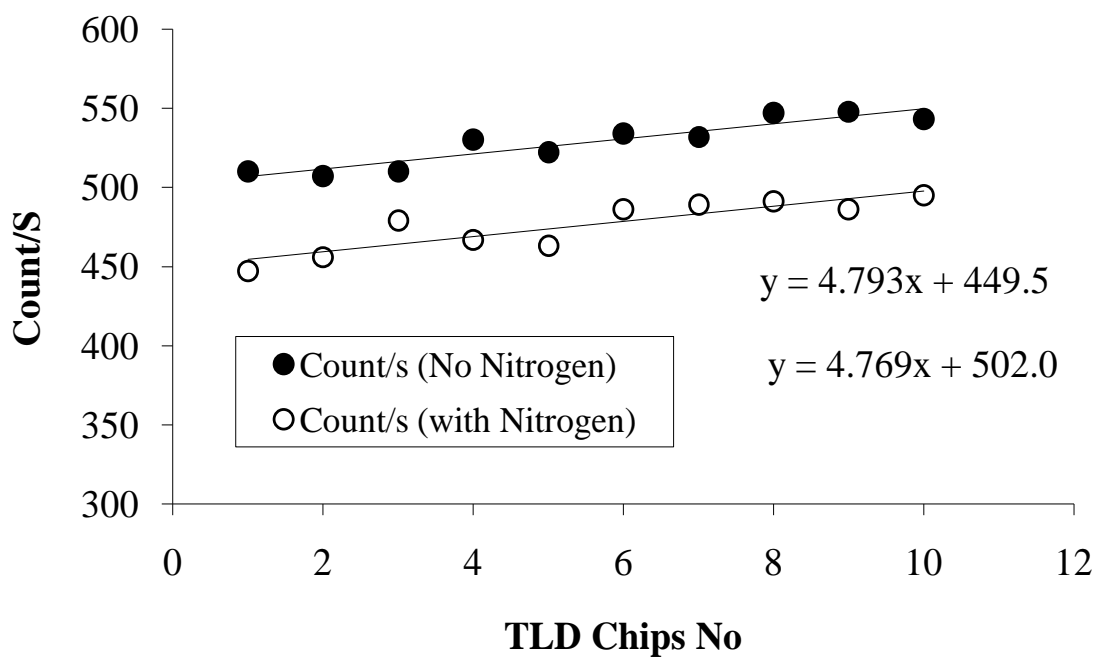

Figure 6. Shows the correlation between the number of TLD chip and the count/s of TLD chips received equal dose $(0.5 \mathrm{mGy})$ with and without Nitrogen flux for crystal cooling and no filter used. 


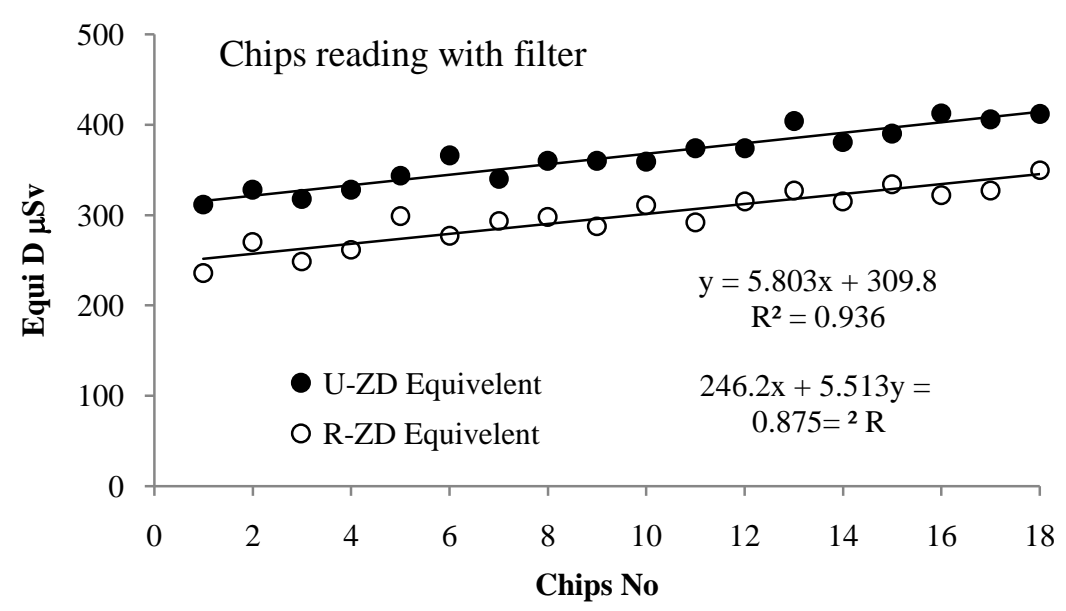

Figure 7. Shows the correlation between the chips Number received equal dose and the dose in $\mu \mathrm{Sv}$ measured by TLD chips before and after annealing (with and without reading zero dose-with filter).

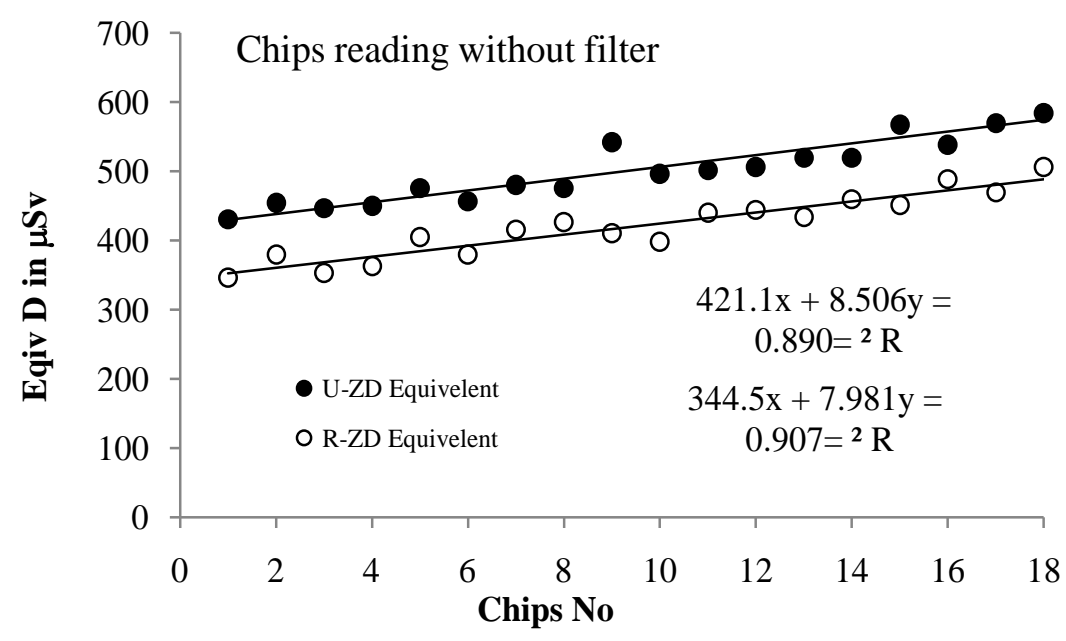

Figure 8. Shows the correlation between the chips Number received equal dose and the dose in $\mu \mathrm{Sv}$ measured by TLD chips before and after annealing (without filter).

500 - $600 \mathrm{~nm}$ originate at TL crystal surface embedded near to gas at $300^{\circ} \mathrm{C}-400^{\circ} \mathrm{C}$ ); as in fact inert gas like $\mathrm{N}_{2}$ allow the surface stored energy in the crystal release with light emission [17] and as well the intrinsic thermoluminescence efficiency; as different crystals have different efficiency for instance: $\mathrm{LiF}, \mathrm{CaF}_{2}: \mathrm{Mn}$, and $\mathrm{CaSO}_{4}$ have $0.039 \%$, $0.44 \%$ and $1.2 \%$ respectively [18] and the relative effective atomic number $\left(Z_{\text {eff }}\right)$ are: $8.31,16.9,15.62$ respectively [19]. Figure 8 shows the correlation between the chips number received equal doses ( $0.5 \mathrm{mGy}$ ) and the dose in $\mu \mathrm{Sv}$ measured by TLD chips before and after annealing (with and without reading zero dose-Filtered). It reveals that: the doses measured without annealing i.e. unread of zero doses, were so greater than that measured with annealing (reading of zero doses); this is due to accumulation of dose in case of reading without annealing (without reading zero dose) as the annealing usually empted and releasing the stored energy in the TLD chips [20]. Also it was so obvious that: there was slightly increment in the dose as there were more chips being read, such increment could be ascribed to suboptimum annealing of the chips. Figure 9 
shows the dose in $\mu \mathrm{Sv}$ measured by TLD chips before and after annealing i.e. with and without zero dose reading (with and without filter). The data analysis reveals that: in case of TLD chips reading without annealing, usually gives greater dose (510.5 $\mu \mathrm{Gy})$ compared with chips reading with annealing $(428.3 \mu \mathrm{Gy})$ with notation that: there was no filter used; hence the annealing causes a reduction in dose by $82.2 \mu \mathrm{Gy}$, although this amount of dose depends on the environment to which the TLD crystal exposed before being used in experiment, however in case of using filter before and after annealing, the chips reading were 370.8 and $304.1 \mu \mathrm{Gy}$ respectively i.e. there was $66.7 \mu \mathrm{Gy}$ as reduction due to filtration; therefore the analysis deduced that: the effect of annealing was greater than the effect of filtration, such results is agree with the state mentioned by Khan, [13]. Figure 10: shows the scanning electron microscope image of LiF:Mg:Ti (a) annealed and before irradiation (b) annealed and after irradiation of $15 \mathrm{~Gy}$. It revealed that: the morphology of LiF:Mg:Ti crystal appeared as more clear with no darkening in its surface compared with that appeared in (b). In such view and since the high temperature would altered the thermoluminiscence glow curve after irradiation, and as well

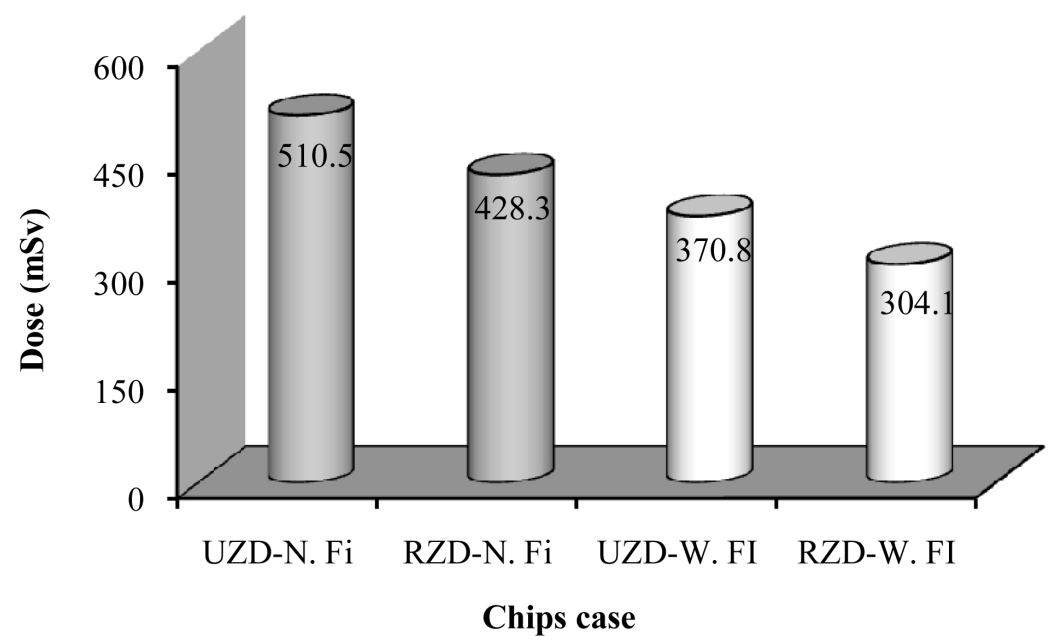

Figure 9. Shows the dose in $\mu$ Sv measured by TLD chips before and after annealing (with and without reading zero doses-with and without filter).
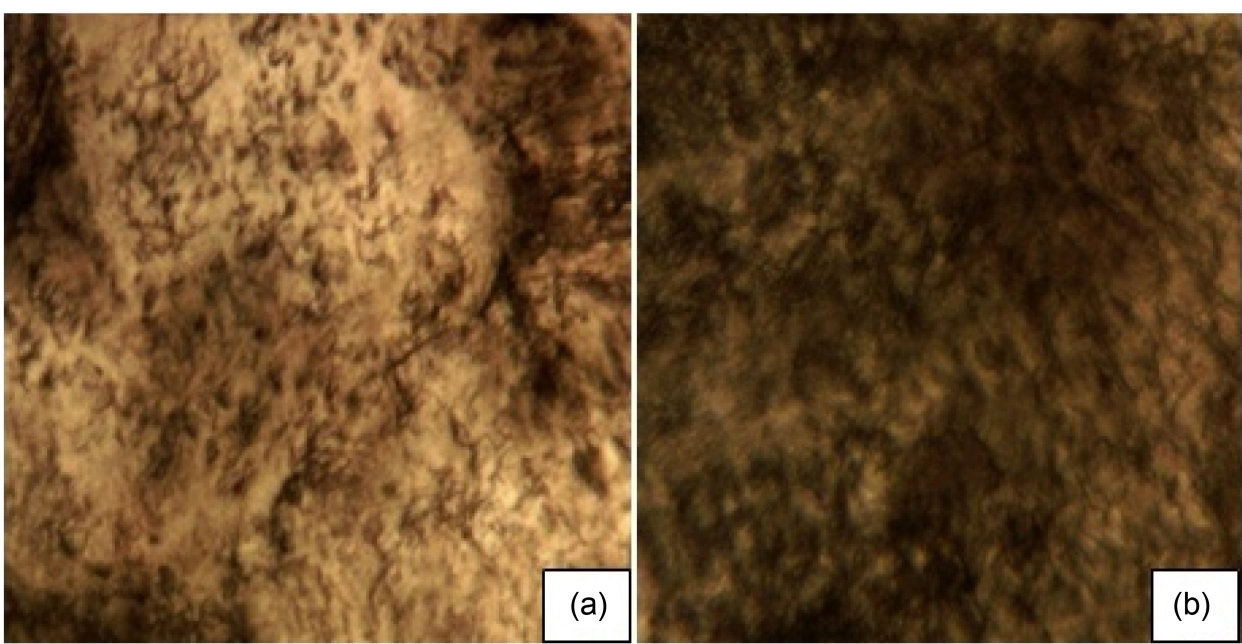

Figure 10. Shows the scanning electron microscope image of LiF:Mg:Ti (a) annealed and before irradiation, (b) annealed and after irradiation of $15 \mathrm{~Gy}$. 
the energy band gap (Eg) for the TLD crystal influenced by irradiation i.e. the pure TLD crystal before irradiation, it's Eg would be in the range of solid state, while after irradiation it's Eg decreases to be in the range of semiconducting material due to immigration of electrons from valence band towards conduction band and trapped in the forbidden band; hence the assumption of radiation induce opacity and crystallization changes in TLD crystal are inevitable which are in turn will affect the accuracy of TLD crystal radiation measurement after long period of application or specific radiation dose.

\section{References}

[1] Tochilin, E., Goldstein, N. and Miller, W.G. (1969) Beryllium Oxide as a Thermoluminescent Dosimeter. Health Physics, 16, 1-7. https://doi.org/10.1097/00004032-196901000-00001

[2] Fowler, J.F. and Attix, F.H. (1966) Solid State Integrating Dosimeters. In: Attix, F.H. and Roesch, W.C., Eds., Radiation Dosimetry, 2nd Edition, Vol. 2, Academic Press, New York, Chap. 14.

[3] Yamashita, T., Nada, N., Onishi, H. and Kitamura, S. (1971) Calcium Sulfate Activated by Thulium or Dysprosium for Thermoluminescence Dosimetry. Health Physics, 21, 295-300. https://doi.org/10.1097/00004032-197108000-00016

[4] Al-Haj, A.N. and Lagarde, C.S. (2004) Glow Curve Evaluation in Routine Personal Dosimetry. Health Physics, 86, S15-S19. https://doi.org/10.1097/00004032-200402001-00007

[5] Stadtmann, H., Delgado, A. and Go'mez-Ros, J.M. (2002) Study of Real Heating Profiles in Routine TLD Readout: Influences of Temperature Lags and Non-Linearities in the Heating Profiles on the Glow Curve Shape. Radiation Protection Dosimetry, 101, 141-144. https://doi.org/10.1097/00004032-200402001-00007

[6] Stadtmann, H., Hranitzky, C. and Brasik, N. (2006) Study of Real Time Temperature Profiles in Routine TLD Read Out-Influences of Detector Thickness and Heating Rate on Glow Curve Shape. Radiation Protection Dosimetry, 119, 310-313.

https://doi.org/10.1093/rpd/nci655

[7] Kitis, G. and Tuyn, J.W.N.A. (1998) Simple Method to Correct for the Temperature Lag in TL Glow-Curve Measurements. Journal of Physics D: Applied Physics, 31, 2065-2073. https://doi.org/10.1088/0022-3727/31/16/017

[8] Pradhan, A.S. and Bhatt, R.C. (1979) Metal Filters for the Compensation of Photon Energy Dependence of the Response of CaS04: Dy-Teflon TLD Discs. Nuclear Instrumentation and Methods, 166, 497-501. https://doi.org/10.1016/0029-554X(79)90540-8

[9] Leon, B.W. (2009) Using Thermoluminescent Dosimeters to Measure the Dose from High and Low Energy X-Ray Sources. UNLV Theses, Dissertations, Professional Papers, and Capstones, Paper 1203.

[10] Lee, Y., Won, Y. and Kang, K. (2015) A Method to Minimize the Fading Effects of LiF:Mg, Ti (TLD-600 and TLD-700) Using a Pre-Heat Technique. Radiation Protection Dosimetry, 164, 449-455. https://doi.org/10.1093/rpd/ncu302

[11] Zimmerman, D.W., Rhyner, C.R. and Cameron, J. (1966) Thermal Annealing Effects on the Thermoluminescence of LiF. Health Physics, 12, 525-531. https://doi.org/10.1097/00004032-196604000-00007

[12] Dahoud, M. and Mustafa, I. (2014) Radiation Dosimetry by TLDs Inside Human Body Phantom While Using 192Ir HDR in Breast Brachytherapy. International Journal of Scientific \& Technology Research, 3, 172-176.

[13] Faiz, K. (2010) The Physics of Radiation Therapy. 4th Edition, Lippincott Williams \& Wil- 
kins, Philadelphia.

[14] Savva, A. (2010) Personnel TLD Monitors, Their Calibration and Response. MSc Dissertation, University of Surrey, Guildford.

[15] Pradhan A.S., Gopalakrishnan, A.K. and Iyer, P.S. (1992) Dose Measurement at High Atomic Number Interfaces in Megavoltage Photon Beams Using TLDs. Medical Physics, 19, 355-356. https://doi.org/10.1118/1.596909

[16] Toktamiş, H. and Necmeddin Yazici, A. (2012) Effects of Annealing on Thermoluminescence Peak Positions and Trap Depths of Synthetic and Natural Quartz by Means of the Various Heating Rate Method. Chinese Physics Letters, 29, Article ID: 087802. https://doi.org/10.1088/0256-307X/29/8/087802

[17] Attlx, F. (2004) Introduction to Radiological Physics and Radiation Dosimetry. Wiley, Hoboken.

[18] Lucke, W.C. (1970) Intrinsic Efficiency of Thermoluminescent Dosimetry Phosphors. Report 7104, Naval Research Laboratory, Washington DC.

[19] Bos, A.J. (2001) High Sensitivity Thermoluminescent Dosimetry. Nuclear Instruments and Methods in Physics Research Section B, 184, 3-28. https://doi.org/10.1016/S0168-583X(01)00717-0

[20] Bilskia, P., Bergerb, T., Hajekc, M., Twardaka, A., Koernerb, C. and Reitz, G. (2013) Thermoluminescence Fading Studies: Implications for Long-Duration Space Measurements in Low Earth Orbit. Radiation Measurements, 56, 303-306.

https://doi.org/10.1016/j.radmeas.2013.01.045

Submit or recommend next manuscript to SCIRP and we will provide best service for you:

Accepting pre-submission inquiries through Email, Facebook, LinkedIn, Twitter, etc. A wide selection of journals (inclusive of 9 subjects, more than 200 journals)

Providing 24-hour high-quality service

User-friendly online submission system

Fair and swift peer-review system

Efficient typesetting and proofreading procedure

Display of the result of downloads and visits, as well as the number of cited articles

Maximum dissemination of your research work

Submit your manuscript at: http://papersubmission.scirp.org/

Or contact ojbiphy@scirp.org 